\title{
A study of operators' computing efficiency with special focus on the readability under different viewing angles of a desktop
}

\author{
Z. Maillck $\cdot$ Mohammad Asjad
}

Received: 5 February 2014/Accepted: 23 July 2014/Published online: 11 September 2014

(C) The Author(s) 2014. This article is published with open access at Springerlink.com

\begin{abstract}
The main objective of this work is to determine the reading performance of operators' under different viewing angles of a desktop computer. The effects of text/ background color, viewing distance and character size on the speed of reading were investigated. The text and/or the background color combination were varied, with constant luminance contrast. Performance was recorded in terms of words per minutes. Standard workplace design recommendations to position center of visual display terminal $15^{\circ}$ and $40^{\circ}$, below horizontal eye level, were taken up for a visually intensive readability task. An orthogonal array, signal-to-noise ratio and the analysis of variance were carried out to investigate the above mentioned operating parameters to determine optimum readability performance. The results suggested that performance was better at $15^{\circ}$ viewing angle as compared to $40^{\circ}$.
\end{abstract}

Keywords Readability - Signal-to-noise (S/N) ratio . Analysis of variance (ANOVA) - Text/background color · Viewing distance $\cdot$ Character size

\section{Introduction}

One of the consequences of the information age is that people increasingly rely on computers to do a variety of everyday jobs, like, reading information through webpages, processing data, writing report, sending e-mail. The

\footnotetext{
Z. Maillck · M. Asjad $(\bowtie)$

Department of Mechanical Engineering, Faculty of Engineering and Technology, Jamia Millia Islamia, New Delhi 110025, India e-mail: masjad@jmi.ac.in

Z. Maillck

e-mail: zmallick2002@yahoo.co.in
}

visual display terminal (VDT) is the primary medium through which humans interact. Studies report readability performance taking into consideration various factors individually or in combination, taking two factors at a time (Legge et al. 1985, 1987). However, combining three or more factors together to assess the influence on operator performance has not been substantially addressed. We used a powerful optimization tool called the Taguchi method for analysis, combining three operating parameters of human computer system to assess the readability performance of operators. Many operating parameters may be combined together but complications in deriving true results out of all these factors restrict one to consider few parameters and also few levels at a time. The Taguchi method is a powerful tool for optimizing design as well as operating parameters. In Ergonomics/Human Factors, use of this optimization tool is still in infancy. Use of this optimization tool will probably obtain better results. The numerous studies pertaining to application of optimization in different areas are available in the literature (Bashiri et al. 2013; Mariajayaprakash et al. 2013; Bashiri and Moslemi 2013; Ghasemi et al. 2013; Shokuhfar et al. 2008; Farsani et al. 2001).

The Taguchi method is a well-known technique that provides a systematic and efficient methodology for process/design optimization. It has been widely used for product design and process optimization worldwide (Wang and Tarng 1998; Chung-Chen and Hong 2002; Nian et al. 1999). This is due to the advantages of the design of experiment using Taguchi's technique, which includes simplification of experimental plan and feasibility of study of interaction between different parameters. Lesser number of experiments means time and costs are reduced. Taguchi proposes experimental plan in terms of orthogonal array that gives different combinations of parameters and their levels for each experiment. According to this technique, the 
entire parameter space is studied with minimal number of necessary experiments (Roy 2001; Phadke 1989). Based on the average output value at each parameter level, main effect analysis is performed. Analysis of variance (ANOVA) is then used to determine which process parameter is statistically significant and the contribution of each process parameter toward the output characteristics. With the main effect and ANOVA analysis, possible combination of optimum parameters can be predicted. Finally, a confirmation experiment is conducted to verify the optimal process parameters obtained from the process parameter design.

Numerous reports say that continuous use of computer causes occupational problems and high level of discomfort to human eyes (Grandjean 1980; Zhu and Wu 1990). The development in information system design suggests that visual display units (VDUs) will continue to be used as a medium for presentation of large amount of connected texts as in videotext, electronic journals, dynamic books or such similar applications. With the passage of time the user interaction with their machines is increasing. This exposure to VDUs may bring in unheard kind and extent of effects that might lead to damage or impairment of human health. Various parameters may apparently influence the humancomputer interaction (HCI) environment, working postures, distance from the VDU, level of illumination in the workplace, color contrast of the background and the projected matter, environmental variables like, noise pollution, temperature, humidity etc. The readability performance of operator is significantly dependant on text/background color combination. Sanders and McCormic (1993) have made recommendations regarding the best screen text/ background color combinations including, "avoid using the extremes of the color spectrum, the reds and blues" or "use as few colors as possible". Shieh and Chen (1997) reported that subjects' viewing distance was significantly affected by color combination. Similarly, Wang et al. (2002) also reported that subjects' searching performance on leading display was improving when the color difference of text/ background becomes larger. Wang and Chen (2003) reported recently that the interaction between jump length and color combination of leading display had a significant effect on subjects' reading performance.

It is reported that the background should not be 'emphasized' in screen components, however, a higher contrast should be reserved for screen components to which attention should be drawn (Galitz 1997). Research findings are mixed, but still text/background color combination is an important consideration in VDT design. Some studies have claimed that there is no effect of text/background color combination on readability performance while others reported improvement in the performance with dark characters on a light background (Wang et al. 2002;
Taptagaporn and Saito 1990; Snyderet al. 1990). Shieh and Lin (2000), indicated that visual preference increased with increase in luminance contrast in color combination of text or background. The viewing angle is also an important factor in readability. Leavitt (1995) reported that eye strain symptoms may occur in up to $75 \%$ of all VDT users. Sanders and McCormic (1993) recommended to place the center of the monitor approximately $15^{\circ}$ below horizontal eye level because it allows the operator to assume a comfortable and natural posture. Other researchers reported that blinking rate of an eye is a reliable indicator of dry eyes and visual discomfort (Villanueva et al. 1996). On the other hand, Ankrum and Nemeth (1995) postulated that the user will feel more comfortable while viewing monitor at $40^{\circ}$ thereby reducing static loading of the muscles of the neck, shoulder and back. Turville et al. (1998) investigated the $40^{\circ}$ VDT position and found that it caused greater head tilt angles and higher muscle activity levels for six of the 10 necks. The third variable, viewing distance, is also a critical factor from operators' readability view point. Users must be able to select their preferred viewing distance when using a VDT. Jaschinski-Kruza (1991) showed that healthy subjects, when free to set their own viewing distance, choose distance between 51 and $99 \mathrm{~cm}$ for characters $5 \mathrm{~mm}$ or high. Szeto and Lee (2002) reported a viewing distance of $53.6 \pm 7.4 \mathrm{~cm}$ for desktop computer while making assessment for VDT workstation. Shieh and Chen (1997) found that screen color combination significantly affected viewing distance, with red text on a green background resulting in a shorter viewing distance and a greater standard deviation of viewing distance than other color combination. Also Shieh (2002) found that the mean viewing distance for LCD was $42.3 \mathrm{~cm}$ and viewing distance correlated significantly with subjective visual fatigue. Knoblauch et al. (1991) measured reading rates for texts when character sizes were between $0.15^{\circ}$ and $6^{\circ}$. The highest reading rates were found for high luminance contrast and character sizes between $0.2^{\circ}$ and $1^{\circ}$. Although researches in this particular area are being conducted taking into consideration different factors, a need to optimize operator performance from readability view point taking three factors together was felt and experimental investigation in this case was carried out taking appropriate factors and their levels.

\section{Method}

Subjects

32 Subjects (16 males and 16 females) were recruited from Universiti Sains Malaysia. They were right handed and with a mean age of 25 year $(\mathrm{SD}= \pm 8.25)$, mean weight 
Fig. 1 The workplace arrangement and schematic diagram of experimental set-up

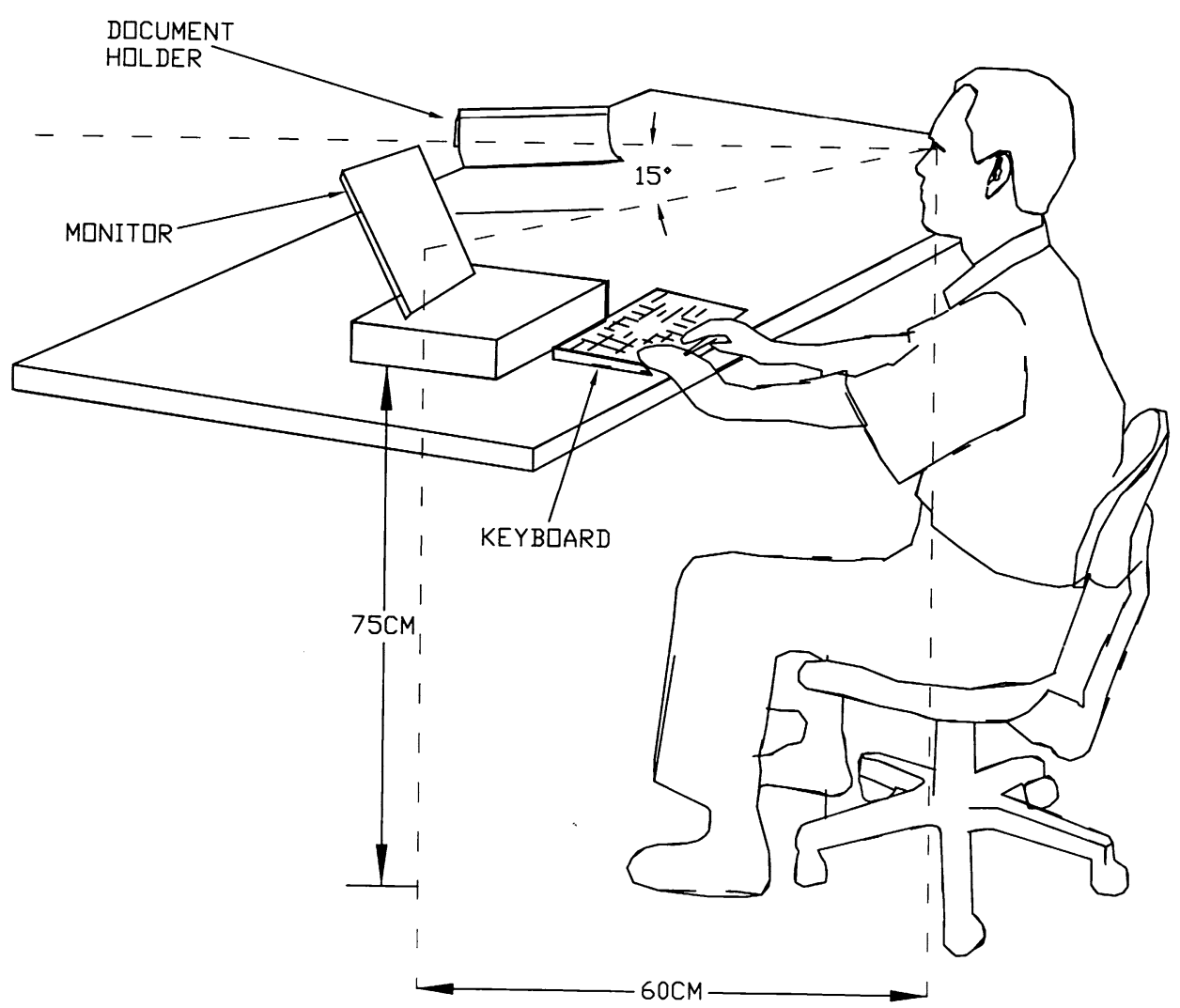

$75.8 \mathrm{~kg}(\mathrm{SD}= \pm 17.2)$. All participants could read Malay fluently. All had 0.8 correct visual acuity or better and normal color vision. Most participants $(90 \%)$ reported reading from computer regularly.

\section{Apparatus and VDT workplace condition}

The experiment was conducted at an adjustable VDT workstation. Text was displayed on a Pentium IV computer, using a $60 \mathrm{~Hz}, 96 \mathrm{dpi} 17$ inch high-resolution RGB monitor. The print was high contrast (Weber contrast 0.94). The luminance contrast between the characters and background was kept nearly constant. The luminance (Y) and CIE chromaticity coordinates $(x, y)$ of white and black for the LCD screen were measured with a Minolta analyzer CS-100. Measurements were done in similar lighting conditions. Photometric readings were measured from the center of the display for both text and background. The monitor was placed on a table $73 \mathrm{~cm}$ in height. The front edge of table was $35 \mathrm{~cm}$ from the screen center. The distance from the participants' eyes to the screen center was 40,50 and $60 \mathrm{~cm}$ respectively in different experiments and measured by an auto focusing video recorder. The inclination of monitor was $105^{\circ}$. Two monitor placements were used for this study, $15^{\circ}$ and $40^{\circ}$ below the horizontal line of sight. The workplace was illuminated by fluorescent tube.
The lamps were covered with a shield and number of lamps was increased to make the ambient illuminance about 350 lux. The workplace arrangement is shown in Fig. 1.

Task and procedure

The stimuli presented to the subjects on the LCD screen were in Malay language, written in usual Roman script, and spacing between the lines was $1 \mathrm{~mm}$. The characters per screen of text were arranged in 25 lines. Three texts of required length were presented to the subjects for readability task to avoid any learning effect included in the experiment. Subjects were instructed to scroll through the stimuli by clicking the down arrow button on the key board as they read. For specific viewing distance, the letter size required was adjusted and presented to the subjects. Each combination number was repeated three times with stated parameter maintained at the required level. To familiarize with the procedure of experiment, subjects were required to perform readability task prior to the actual experiment. Each combination number was repeated three times thus consuming a total of $9 \mathrm{~min}$ ( $3 \mathrm{~min}$ each time) to complete one set of experiment. Subjects started reading task as they heard the instruction "START" and stopped as they heard "STOP". Thus readability performance in number of words per minute (WPM) was obtained by selecting the 
total passage read divided by time taken. Table 3, shows the performance in WPM as the average of the three observations, with fraction part omitted, for $15^{\circ}$ viewing angle while similar experiments were carried out for $40^{\circ}$ viewing angle. Duration of experiment for all sets of 9 combinations was $81 \mathrm{~min}$ as each participant repeated the task 3 times in one particular setting of experiment. Juola et al. (1995) reported that speed of 260 and $171 \mathrm{wpm}$ had no significant effect on subjects' reading accuracy. Similarly, in this experiment, subjects made negligible reading error. Note that the inter-individual differences were not taken into account while determining stimulus parameters.

Selection of parameters and their levels

The readability performance experiments were carried out in the School of Mechanical Engineering, Universiti Sains Malaysia, in a computer room under above stated conditions. The initial operating parameters are based on the normal working of human-machine system. In the existing human-computer interaction conditions for subjects, their performance in terms of words per minute (WPM) were found to be $190 \pm 10$ WPM, without specifying the values of parameters under consideration. For determining the base line values, selected subjects were asked to perform readability task by adjusting their parameters according to their convenience and on the basis of this it was found that values of the parameters under reference were not fixed. However, luminance contrast $=0.12 \pm 0.04$, viewing distance $=47 \pm 13 \mathrm{~cm}$ and character size $=1.6 \pm 1.2$ degree were noted. While keeping the other parameters same as for other experiments, the readability performances of the subjects were evaluated and it was found as $190 \pm 10$ WPM. Different values of text/background color combination, viewing distance and character size were selected after extensive literature review and surveys. For example, Legge et al. (1987) investigated the reading rates for moving lines of texts and found that maximum reading rates were achieved at character sizes of $0.3^{\circ}-2^{\circ}$ regardless of the polarity of the text. Similarly Knoblauch et al. (1991) measured reading rates for texts and found the character for which the highest reading rates were achieved increased from $0.2-1$ to $2-4^{\circ}$. Based on the above findings, character sizes chosen for present study were $0.2^{\circ}, 1.5^{\circ}$ and 4 . Wang and Chen (2003) reported the interaction between text/ background color combination with jump length for Chinese typography and found that when jump length was at a higher level subjects' reading performance for the text/ background color combinations with higher color difference was significantly better than performance for the color combinations with lower color difference. Similarly, Wang et al. (2002) also reported that subjects' searching performance on leading display was improving when the color
Table 1 Operating parameters and their levels

\begin{tabular}{llllll}
\hline Symbol & $\begin{array}{l}\text { Operating } \\
\text { parameters }\end{array}$ & Unit & Level 1 & Level 2 & Level 3 \\
\hline A & $\begin{array}{l}\text { Text/background } \\
\text { color }\end{array}$ & - & $\begin{array}{c}\text { White- } \\
\text { on- } \\
\text { black }\end{array}$ & $\begin{array}{c}\text { Blue- } \\
\text { on- } \\
\text { yellow }\end{array}$ & $\begin{array}{c}\text { Black- } \\
\text { on- } \\
\text { white }\end{array}$ \\
& combination & & & & \\
B & Viewing distance & cm & 40 & 50 & 60 \\
C & Character size & $\circ$ & 0.2 & 1.5 & 4 \\
\hline
\end{tabular}

difference of text/background becomes larger. Thus, there has been a need to discuss the effect of text/background color combination on subjects' reading performance. Therefore, higher color combination has been chosen for this study, i.e., white-on-black, black-on-white and blueon-white. Viewing distance adopted by the operators varied from study to study and no conclusive result has been reported. Therefore, in the present study a range of values related to viewing distance was chosen, i.e., 40, 50 and $60 \mathrm{~cm}$. The selected parameter and their respective values (levels) have been shown in Table 1.

\section{Determination of optimal operating parameters}

In this section, the use of an orthogonal array to reduce the number of experiments for determining the operating parameters is reported. Results of readability performance (in number of words read per minute) experiments are analyzed by the signal-to-noise $(\mathrm{S} / \mathrm{N})$ ratio and analysis of variance (ANOVA), optimal operating parameters and their levels were determined to maximize the readability performance of the operators without error in a humancomputer interaction kind of working environment. Subsequently a confirmation test was carried out to verify the optimized result.

\section{Orthogonal array experiment}

The selection of orthogonal array to use basically depends on number of factors considered in the study and interaction of interest, number of levels for the factors of interest and desired experimental resolution or cost limitations.

To select an appropriate orthogonal array for experiments, the total degrees of freedom need to be determined. The degree of freedom is defined as the number of comparisons between operating parameters to be made to determine which level is better and specifically how much better. For example, a three level process parameter counts for two degrees of freedom. In the present study, since each parameter has three levels therefore, there are six degrees of freedom due to the three parameters in the readability performance operation. The degree of freedom for the orthogonal array should be greater than or at least equal to 
Table 2 Experimental layout using an $\mathrm{L}_{9}$ orthogonal array

\begin{tabular}{llll}
\hline $\begin{array}{l}\text { Combination } \\
\text { number }\end{array}$ & \multicolumn{2}{l}{ Operating parameter levels } \\
\cline { 2 - 4 } & $\begin{array}{l}\text { A } \\
\text { Text/background color } \\
\text { combination }\end{array}$ & $\begin{array}{l}\text { B } \\
\text { Viewing } \\
\text { distance }\end{array}$ & $\begin{array}{l}\text { C } \\
\text { Character } \\
\text { size }\end{array}$ \\
\hline 1 & 1 & 1 & 1 \\
2 & 1 & 2 & 2 \\
3 & 1 & 3 & 3 \\
4 & 2 & 1 & 3 \\
5 & 2 & 2 & 1 \\
6 & 2 & 3 & 2 \\
7 & 3 & 1 & 2 \\
8 & 3 & 2 & 3 \\
9 & 3 & 3 & 1 \\
\hline
\end{tabular}

those for operation parameters. In this study, an $\mathrm{L}_{9}$ orthogonal array is used and shown in Table 2. Detail related to orthogonal array selection for specific problem can be found in Roy (2001); Ross (1996).

\section{Data collection}

Before starting the actual experiment, a trial experiment was performed to familiarize the participants with the way they will perform the experiment. Nine experiments as per the plan shown in Table 2 were performed. Each experiment was repeated three times and number of words read per minute was obtained. While calculating number of words per minute, fractional values were not considered. The overall experimental results are shown in Table 3 for $15^{\circ}$ viewing angle (Experiment-1) and for $40^{\circ}$ viewing angle (experiment-2). Signal-to-noise ratio measures the sensitivity of the quality investigated to those uncontrollable factors in the experiment. The higher value of $\mathrm{S} / \mathrm{N}$ ratio is desirable because greater $\mathrm{S} / \mathrm{N}$ ratio will result in smaller product variance around the target value. Mathematical formula to calculate $\mathrm{S} / \mathrm{N}$ ratio has been given in the following section. Table 4 shows the respective $\mathrm{S} / \mathrm{N}$ ratios for experiment-1 and experiment-2. Tables 5 and 6 show the $\mathrm{S} / \mathrm{N}$ ratio response table for the $15^{\circ}$ and $40^{\circ}$ viewing angles' experiments, respectively.

\section{Results and discussion}

The Taguchi method as explained in introduction section is a powerful tool for design as well as process optimization (Wang and Tarng 1998; Chung-Chen and Hong 2002; Nian et al. 1999). The purpose of process optimization is to determine the factor levels that can generate the best performance of the process under study. In this study, use of this quality tool has been made for process optimization combining several factors together i.e. text/background color, viewing distance and character size.

The Taguchi method uses the $\mathrm{S} / \mathrm{N}$ ratio to measure the deviation of quality characteristics from the desired value. In the Taguchi method, the term signal represents the desirable value (mean) for the output characteristics. Therefore, the $\mathrm{S} / \mathrm{N}$ ratio, $\eta$ is the ratio of the mean and Standard deviation. Taguchi uses the $\mathrm{S} / \mathrm{N}$ ratio to measure the quality characteristics deviating from the desired value. The value of $\mathrm{S} / \mathrm{N}$ ratio is calculated using the Eqs. (1) and (2) given below. It can be defined using the following equation:

$\eta=-10 \log (\mathrm{MSD})$

where, $\mathrm{MSD}=$ mean square deviation for the output characteristics. There are three categories of performance characteristics; namely, the-lower-the-better, the-higherthe-better and the-nominal-the-better. To obtain the higher readability performances, the-higher-the-better
Table 3 Experimental result for readability task performance $\left(15^{\circ}\right)$

\begin{tabular}{|c|c|c|c|c|c|c|c|}
\hline \multirow[t]{2}{*}{$\begin{array}{l}\text { Combination } \\
\text { number }\end{array}$} & \multirow{2}{*}{$\begin{array}{l}\text { A } \\
\text { Text/background color } \\
\text { combination }\end{array}$} & \multirow{2}{*}{$\begin{array}{l}\text { B } \\
\text { Viewing } \\
\text { distance } \\
(\mathrm{cm})\end{array}$} & \multirow{2}{*}{$\begin{array}{l}\text { C } \\
\text { Character } \\
\text { size }\left(^{\circ}\right)\end{array}$} & \multicolumn{4}{|c|}{$\begin{array}{l}\text { Readability performance in } \\
\text { Words Per Minute (WPM) }\end{array}$} \\
\hline & & & & $\begin{array}{l}1 \\
\text { (average) }\end{array}$ & 2 & 3 & 4 \\
\hline 1 & White-on-black & 40 & 0.20 & 198 & 210 & 205 & 204 \\
\hline 2 & White-on-black & 50 & 1.50 & 210 & 215 & 200 & 208 \\
\hline 3 & White-on-black & 60 & 4.00 & 225 & 215 & 200 & 213 \\
\hline 4 & Blue-on-yellow & 40 & 4.00 & 230 & 225 & 210 & 221 \\
\hline 5 & Blue-on-yellow & 50 & 0.20 & 170 & 150 & 175 & 165 \\
\hline 6 & Blue-on-yellow & 60 & 1.50 & 235 & 230 & 232 & 232 \\
\hline 7 & Black-on-white & 40 & 1.50 & 240 & 235 & 230 & 235 \\
\hline 8 & Black-on-white & 50 & 4.00 & 250 & 240 & 240 & 243 \\
\hline 9 & Black-on-white & 60 & 0.20 & 235 & 216 & 225 & 225 \\
\hline
\end{tabular}


Table 4 S/N ratio for different parameters for different viewing angles

Table $5 \mathrm{~S} / \mathrm{N}$ response table for readability performance $\left(15^{\circ}\right.$ viewing angle)

\begin{tabular}{llllll}
\hline Symbol & Operating parameters & \multicolumn{4}{l}{ Mean S/N ratio (dB) } \\
\cline { 3 - 6 } & & $\begin{array}{l}\text { Level } \\
1\end{array}$ & $\begin{array}{l}\text { Level } \\
2\end{array}$ & $\begin{array}{l}\text { Level } \\
3\end{array}$ & $\begin{array}{l}\text { Max- } \\
\text { min }\end{array}$ \\
\hline A & $\begin{array}{c}\text { Text/background color } \\
\text { combination }\end{array}$ & 46.40 & 46.19 & 47.42 & 1.23 \\
& Viewing distance & 46.86 & 46.19 & 46.95 & 0.76 \\
B & Character size & 46.74 & 47.18 & 47.08 & 0.34 \\
\hline
\end{tabular}

Table 6 S/N response table for readability performance $\left(40^{\circ}\right.$ viewing angle)

\begin{tabular}{llllll}
\hline Symbol & Operating parameters & \multicolumn{4}{l}{ Mean S/N ratio $(\mathrm{dB})$} \\
\cline { 3 - 6 } & & $\begin{array}{l}\text { Level } \\
1\end{array}$ & $\begin{array}{l}\text { Level } \\
2\end{array}$ & $\begin{array}{l}\text { Level } \\
3\end{array}$ & $\begin{array}{l}\text { Max- } \\
\text { min }\end{array}$ \\
\hline A & $\begin{array}{c}\text { Text/background color } \\
\text { combination }\end{array}$ & 45.44 & 45.60 & 46.81 & 1.37 \\
& Viewing distance & 45.85 & 45.44 & 46.55 & 1.11 \\
B & Character size & 45.08 & 45.59 & 47.15 & 2.07 \\
\hline
\end{tabular}

characteristics for readability performance should be taken. The MSD for higher-the-better quality characteristics can be expressed as:

$\operatorname{MSD}=1 / n \sum 1 / R^{2}$

where, $n=$ number of observations and $R=$ the average number of WPM. The $\mathrm{S} / \mathrm{N}$ ratio, $\eta$ for the nine experiments was calculated using the above two formulae and is shown in Table 4 for both the experiments. Since the experimental design (Table 2) is orthogonal, it is then possible to separate out the effect of each operational parameter at different levels. For example, the mean $\mathrm{S} / \mathrm{N}$ ratio for text/background color at levels 1,2 and 3 can be calculated by averaging the $\mathrm{S} / \mathrm{N}$ ratio for experiment number $1-3,4-6$

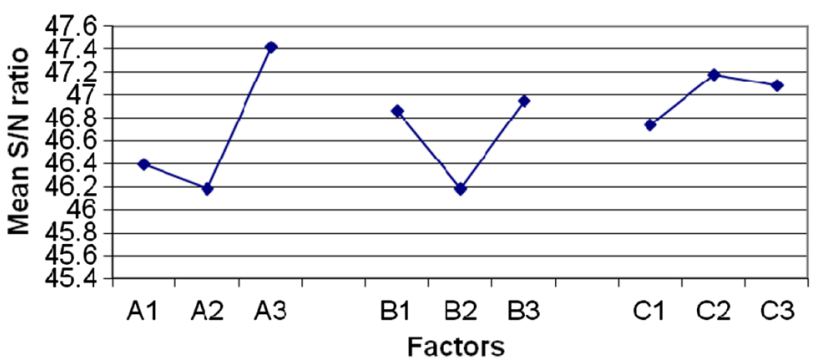

Fig. 2 S/N graph showing readability performance for factors A, B and $C\left(15^{\circ}\right.$ viewing angle $)$

and 7-9, respectively (Table 2). The mean of the multiresponse $\mathrm{S} / \mathrm{N}$ ratio for each level of the other operating parameters can be computed in a similar manner. The respective factors and their corresponding $\mathrm{S} / \mathrm{N}$ ratio values have been shown graphically in Figs. 1 and 2 respectively. Tables 5, 6 show mean $\mathrm{S} / \mathrm{N}$ ratio for each parameter at three different levels for experiment 1 and 2 respectively. From these tables the highest value for each mean $\mathrm{S} / \mathrm{N}$ ratio for each operating parameters can be identified clearly. In experiment-1, text/background color at level 3 (blue-onwhite), viewing distance at level $3(60 \mathrm{~cm})$ and character size at level $2(1.5 \mathrm{deg}$.) give the highest value. On the other hand, text/background color at level 3 (black-onwhite), viewing distance at level $3(60 \mathrm{~cm})$ and character size at level $3\left(4^{\circ}\right)$ give the highest values for experiment-2. In both the studies, the text/background color at level 3 (black-on-white) gave the optimum performance (maximum number of WPM). This result is consistent with the finding of Wang et al. (2002), Wang and Chen (2003). Similarly, in both the experiments it was found that preferable viewing distance is $60 \mathrm{~cm}$. This finding is in agreement with Jaschinski-Krutz (1991; Szeto and Lee (2002); Jaschinski-Kruza (1998).Viewing distance may reflect the appropriateness of various aspects of VDT design. The character size varied from $0.2^{\circ}$. to $4.00^{\circ}$ for obtaining the maximum readability performance in the two experiments conducted. This is in agreement with results obtained by Knoblauch et al. (1991); Ojanpaa and Nasanen (2003). The finding of this work in terms of preferred viewing angle adopted by the subjects to give better readability performance is $15^{\circ}$. Various viewing angles were suggested but it was found that subjects preferred $15^{\circ}$ viewing angle (Turville et al. 1998). Figures 2 and 3, show the $\mathrm{S} / \mathrm{N}$ graph for the experimental results. Regardless of the lower-the- better or higher-the-better performance characteristics, the larger the multi-response $\mathrm{S} / \mathrm{N}$ ratio, the smaller is the variance of performance characteristics around the desired value. However, the relative percentage contribution of each parameter toward optimum performance characteristics still needs to be known so that the 


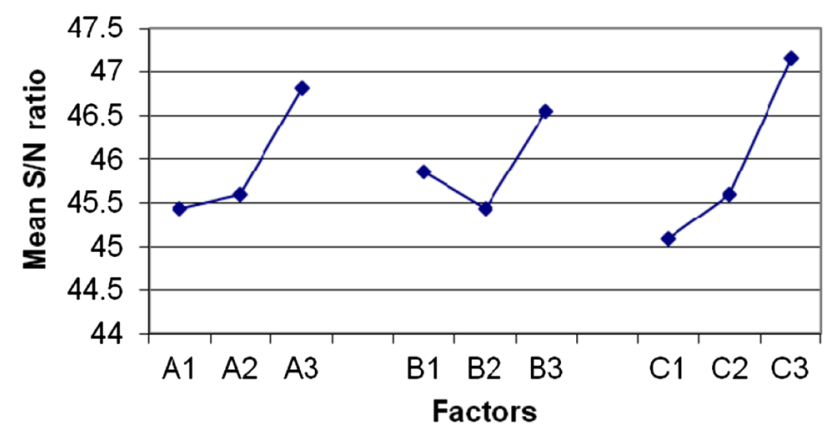

Fig. 3 S/N graph showing readability performance for factors A, B and $\mathrm{C}\left(40^{\circ}\right.$ viewing angle)

optimal combinations of the operating parameters and their levels can be determined more accurately.

\section{Analysis of variance (ANOVA)}

The purpose of carrying out ANOVA is to investigate which of the operation parameters significantly affects the performance characteristics. Tables 7 and 8 show the results of analysis of variance. Statistically, $F$ test can be used to determine which operating parameters have significant effect on the readability performance. In the F-test, mean square (MS) due to each operating parameters needs to be calculated. The MS is equal to the sum of the squared deviations divided by the degrees of freedom associated with the operating parameters. The $\mathrm{F}$ value for each operating parameter is a ratio of the MS to the mean square of error. The larger the $\mathrm{F}$ value, the greater the effect on the performance characteristics (no of words read per minute) due to the change of operating parameters. Usually, when $F>4$ it means that the change of process parameter has a significant effect on the quality characteristic (Wang and Tarng 1998). From the results of the ANOVA presented in Tables 7, 8, it can be seen that none of the process parameter is statistically significant. However, each parameter contributes to the quality characteristics (maximum number of words read per minute). The contribution order for experiment-1 is: text/background color $(40.55 \%)$, viewing distance $(10.61 \%)$ and character size $(45.13 \%)$. Similarly, the contribution order for experiment-2 is: text/background color $(35.70 \%)$, viewing distance $(13.45 \%)$ and character size $(45.25 \%)$. Therefore, based on the $\mathrm{S} / \mathrm{N}$ ratio and ANOVA analyses, the optimal parameters for achieving maximum readability for $15^{\circ}$ viewing angle (Experiment-1) in terms of number of words read per minute were at text/ background color at level 3 i.e. A3 (black-on-white), viewing distance at level 3 i.e. B3 $(60 \mathrm{~cm})$ and character size at level 2 i.e. $\mathrm{C} 2\left(1.5^{\circ}\right)$. The percentage contribution for each factor has been shown in Fig. 4 for experiment-1, and in Fig. 5 for experiment- 2 respectively. Similarly, on the basis of $\mathrm{S} / \mathrm{N}$ ratio and ANOVA analyses, the optimal parameters obtained for experiment-2, were $\mathrm{A} 3 \mathrm{~B} 3 \mathrm{C} 3$. It is evident from the results that the character size contributes the most to the readability performance in experiment- 1 as well as experiment-2.

\section{Confirmation test}

Estimated readability performance at optimum condition was calculated by adding the average performance to the contribution of each parameter using the following equations (Phadke 1989).

$Y_{\mathrm{opt}}=m+\left(m_{\mathrm{Aopt}}-m\right)+\left(m_{\mathrm{Bopt}}-m\right)+\left(m_{\mathrm{Copt}}-m\right)$

$m=T / n$

where $m$ is the average performance, $T$ the grand total of average readability performance for each combination, $n$ the total number of combinations and $m_{\text {Aopt }}$ the average readability for parameter $\mathrm{A}$ at its optimum level, $m_{\mathrm{Bopt}}$ the average readability at its optimum level, $m_{\text {Copt }}$ the average readability for parameter $\mathrm{C}$ at its optimum level. For conforming the result predicted, as a rule, the optimum condition will not be one of the experiments already conducted at the optimum condition. So it is a good idea to plan on running an additional few samples at the optimum condition. These confirmation tests serve two purposes. Firstly, they establish the new performance at new (optimum) condition, which can establish the improvement achieved. Secondly, they allow the experimenter to determine how close the estimate is to the results observed (Roy 2001). Expression for calculating the confidence interval is given as:

$\mathrm{CI}=\sqrt{\frac{F(n 1, n 2) x V e}{N e}}$

where $F(n 1, n 2)=$ Tabulated value of $F$-ratio, $\mathrm{Ve}=$ Error variance, $\mathrm{Ne}=$ Number of replications.

For the present study, the CI was calculated considering $95 \%$ level of confidence and repeating the experiment for $15^{\circ}$ viewing angle four times at optimum condition. As results obtained were quite consistent, therefore experiment was not repeated for more number of iterations. Expected result at optimum condition for $15^{0}$ viewing angle was calculated and found to be in between $48.77 \mathrm{~dB}$ $(46.55+2.22)$ and $44.33 \mathrm{~dB}(46.55-2.22)$. Since all the values for $15^{\circ}$ viewing angle (Table 5) were within the upper $(48.77 \mathrm{~dB})$ and lower $(44.33 \mathrm{~dB})$ limit set by calculation, therefore it was concluded that for $95 \%$ of the confidence level experimental results are correct. Similarly for $40^{\circ}$ viewing angle, the calculation was made and it was again found that for a confidence level of $95 \%$ 
Table 7 Result of the analysis of variance for readability performance $\left(15^{\circ}\right.$ viewing angle)

\begin{tabular}{llllllr}
\hline Symbol & Operation parameter & $\begin{array}{l}\text { Degrees of } \\
\text { freedom } \\
(d f)\end{array}$ & $\begin{array}{l}\text { Sum of } \\
\text { square } \\
(\mathrm{SS})\end{array}$ & $\begin{array}{l}\text { Mean } \\
\text { square } \\
(\mathrm{MS})\end{array}$ & $F$ & $\begin{array}{l}\text { Percentage } \\
\text { contribution }\end{array}$ \\
\hline A & $\begin{array}{c}\text { Text/background color } \\
\text { combination }\end{array}$ & 2 & 2.60 & 1.30 & 1.699 & 40.55 \\
& $\begin{array}{l}\text { Viewing distance } \\
\text { B }\end{array}$ & 2 & 1.04 & 0.52 & 0.679 & 10.61 \\
C & Character size & 2 & 3.06 & 1.53 & 2.000 & 45.13 \\
Error & & 2 & 1.53 & 0.765 & & 3.71 \\
Total & & 8 & 8.23 & & & 100.00 \\
\hline
\end{tabular}

\begin{tabular}{llllllr}
\hline Symbol & Operation parameter & $\begin{array}{l}\text { Degrees of } \\
\text { freedom } \\
(d f)\end{array}$ & $\begin{array}{l}\text { Sum of } \\
\text { square } \\
(\mathrm{SS})\end{array}$ & $\begin{array}{l}\text { Mean } \\
\text { square } \\
(\mathrm{MS})\end{array}$ & F & $\begin{array}{l}\text { Percentage } \\
\text { contribution }\end{array}$ \\
\hline A & $\begin{array}{l}\text { Text/background color } \\
\text { combination }\end{array}$ & 2 & 2.84 & 1.42 & 1.82 & 35.70 \\
B & Viewing distance & 2 & 1.16 & 0.58 & 0.743 & 13.45 \\
$\mathrm{C}$ & Character size & 2 & 4.00 & 2.00 & 2.560 & 45.25 \\
Error & & 2 & 1.56 & 0.780 & & 4.60 \\
Total & & 8 & 9.56 & & & 100.00 \\
\hline
\end{tabular}

Table 8 Result of the analysis of variance for readability performance $\left(40^{\circ}\right.$ viewing angle)
Fig. 4 Pie chart showing percentage contribution of factors A $(40.55 \%)$, B $(10.61 \%)$ and $\mathrm{C}(45.13 \%)$ (15 viewing angle)

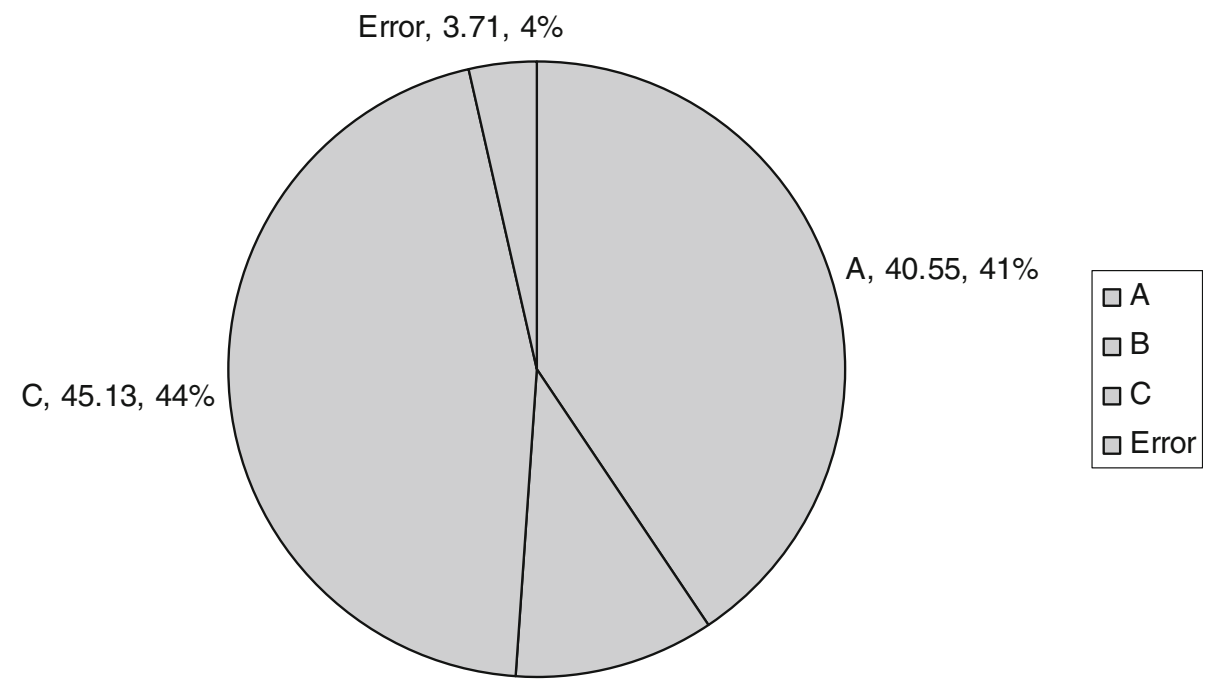

B, $10.61,11 \%$ results were within upper and lower control limit set by calculation.

Once the optimal combination and levels of operational parameters for maximum readability performance in terms of number of words read per minute have been obtained, the final step was to verify the estimated results with the experimental values. Estimated readability performance at optimum condition was calculated by adding the average performance to the contribution of each parameter. Tables 9, 10 show the results of the confirmation experiment using the optimal operating parameters. It can be seen from these tables that the predicted readability performance for the condition $\mathrm{A} 3 \mathrm{~B} 3 \mathrm{C} 2$ for experiment-1 and $\mathrm{A} 3 \mathrm{~B} 3 \mathrm{C} 3$ for experiment- 2 is very close to the experimental value and the increase of the $\mathrm{S} / \mathrm{N}$ ratio from the initial operating parameters to the optimal operating parameter is $1.58 \mathrm{~dB}$ for experiment- 1 and $1.26 \mathrm{~dB}$ for experiment-2. Thus, the method discussed in paper increases the readability performance when the reading task is performed at optimum combination of operating parameters and their levels i.e. A3B3C2 for experiment-1 and A3B3C3 for experiment-2. Based on the result of the confirmation test, the readability is improved from 190 to 225 WPM, in experiment-1; 190-215 WPM, in experiment-2. Figure 6 shows the 
Fig. 5 Pie chart showing percentage contribution of factors A $(35.70 \%)$, B $(13.45 \%)$ and $\mathrm{C}(45.25 \%)$ $\left(40^{\circ}\right.$ viewing angle)

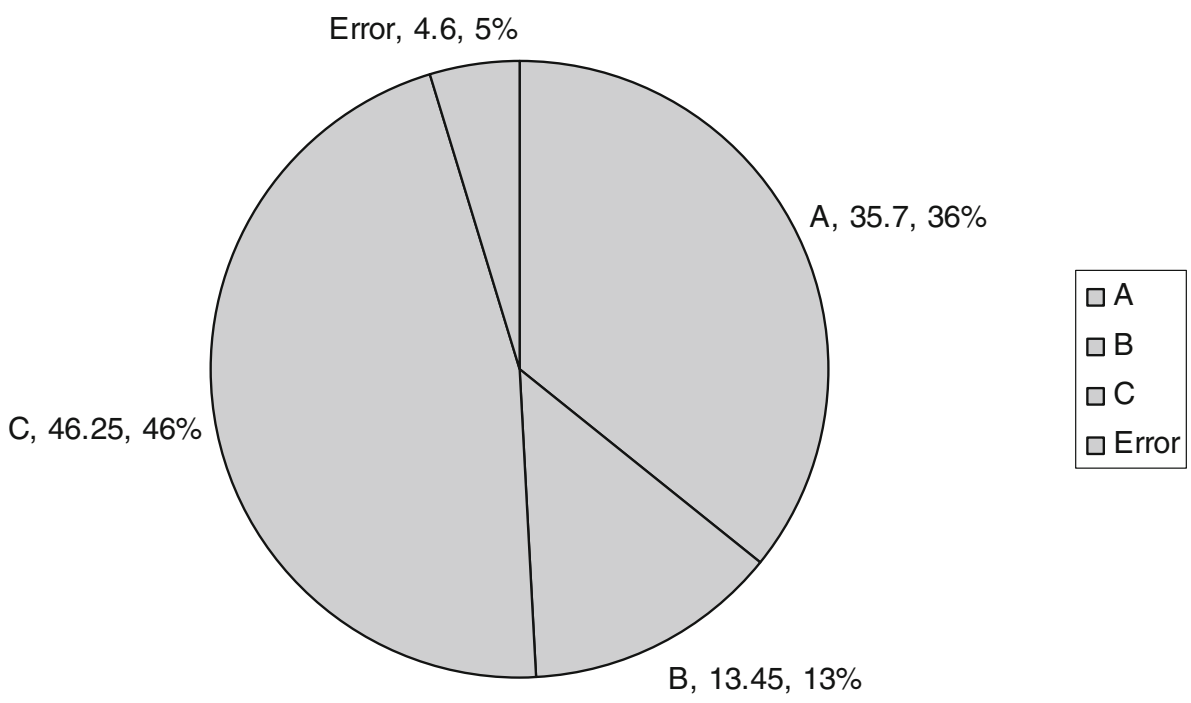

Table 9 Results of confirmation test $\left(15^{\circ}\right.$ viewing angle)

\begin{tabular}{llll}
\hline & $\begin{array}{l}\text { Initial } \\
\text { operating } \\
\text { parameters }\end{array}$ & $\begin{array}{l}\text { Optimal operational } \\
\text { parameters }\end{array}$ & \\
\cline { 3 - 4 } & & Prediction & Experiment \\
\hline $\begin{array}{l}\text { Level } \\
\begin{array}{l}\text { Readability performance } \\
\text { (no of WPM) }\end{array}\end{array}$ & 190.00 & A3B3C2 & A3B3C2 \\
S/N ratio (dB) & 45.57 & 213.00 & 225.00 \\
\hline
\end{tabular}

Improvement of $\mathrm{S} / \mathrm{N}$ ratio $=47.15-45.57=1.58 \mathrm{~dB}$

Improvement in WPM $=225.00-190.00=35 \mathrm{WPM}$

Table 10 Results of confirmation test ( $40^{\circ}$ viewing angle)

\begin{tabular}{|c|c|c|c|}
\hline & \multirow{2}{*}{$\begin{array}{l}\text { Initial } \\
\text { operating } \\
\text { parameters }\end{array}$} & \multicolumn{2}{|c|}{$\begin{array}{l}\text { Optimal operational } \\
\text { parameters }\end{array}$} \\
\hline & & Prediction & Experiment \\
\hline Level & $\mathrm{A} 2 \mathrm{~B} 2 \mathrm{C} 2$ & A3B3C 3 & A3B3C 3 \\
\hline $\begin{array}{l}\text { Readability performance(no } \\
\text { of WPM) }\end{array}$ & 190.00 & 210.00 & 215.00 \\
\hline $\mathrm{S} / \mathrm{N}$ ratio $(\mathrm{dB})$ & 45.57 & 46.16 & 46.83 \\
\hline
\end{tabular}

Improvement of $\mathrm{S} / \mathrm{N}$ ratio $=46.83-45.57=1.26 \mathrm{~dB}$

Improvement in WPM $=215.00-190.00=25 \mathrm{WPM}$

comparative improvement in readability performance for $15^{\circ}$ and $40^{\circ}$ viewing angle experiments.

\section{Conclusions}

The individual influence of the text/background color, viewing distance and character size on the readability performance of the operators of computers have been optimized using Taguchi method. The optimum operating parameters and their levels were found to be $\mathrm{A} 3 \mathrm{~B} 3 \mathrm{C} 2$ i.e. the black-on-white, viewing distance $60 \mathrm{~cm}$, character size $1.5 \mathrm{deg}$, for experiment-1 in which viewing angle was maintained at $15^{\circ}$. Similarly, optimum operating parameters were found to be $\mathrm{A} 3 \mathrm{~B} 3 \mathrm{C} 3$, i.e., the black-on-white, viewing distance $=60 \mathrm{~cm}$ and character size $4.00^{\circ}$ for experiment-2 in which viewing angle was maintained at $40^{\circ}$. In both the studies, text/background color at level 3(black-on-white) gave the optimum performance (maximum number of WPM). This result is consistent with the finding of Sanders and McCormick (1993); Wang et al. (2002); Wang and Chen (2003). Similarly, in both the experiments it was found that preferable viewing distance is $60 \mathrm{~cm}$. This finding is in agreement with JaschinskiKrutz (1991); Szeto and Lee (2002); Jaschinski-Kruza (1998). Viewing distance may reflect the appropriateness of various aspects of VDT design. The character size varied from $0.2^{\circ}$ to $4.00^{\circ}$ for obtaining the maximum readability performance in the two experiments conducted. This is in agreement with results obtained by Knoblauch et al. (1991); Ojanpaa and Nasanen (2003). The finding of this work in terms of preferred viewing angle adopted by the subjects to give better readability performance is $15^{\circ}$. Various viewing angles were suggested but it was found that subjects preferred $15^{\circ}$ viewing angle (Turville et al. 1998). In literature, performance measure is found by combining two factors i.e., luminance contrast with character size or viewing distance with character size but combining three factors together i.e., luminance contrast, viewing distance and character size together did not apparently studied.

Thus, it is clear that if the above mentioned factors are combined together at the appropriate level, the readability 
Fig. 6 Comparison of performance improvement (readability task) For $15^{\circ}$ and $40^{\circ}$ viewing angles

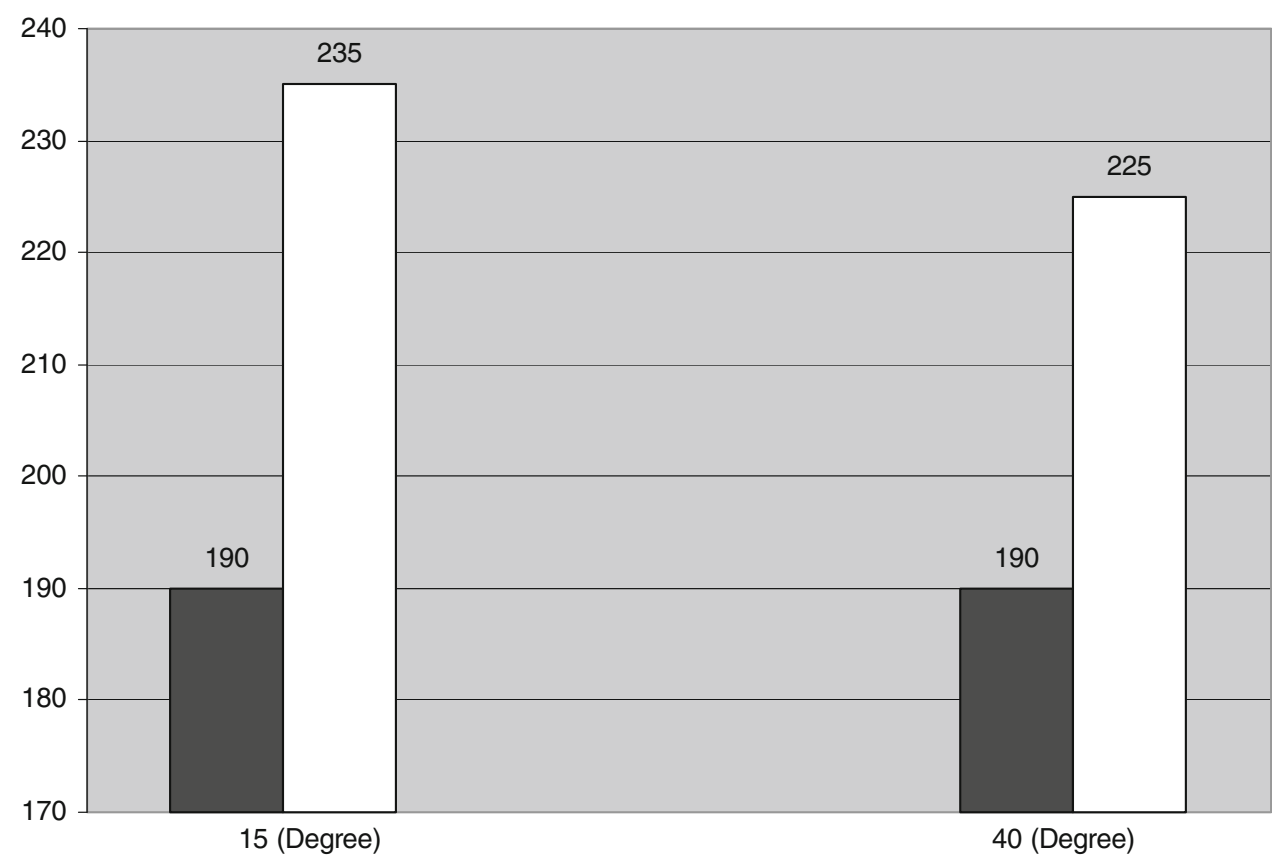

task performance of the operators will improve and the reading time may be reduced.

Open Access This article is distributed under the terms of the Creative Commons Attribution License which permits any use, distribution, and reproduction in any medium, provided the original author(s) and the source are credited.

\section{References}

Ankrum DR, Nemeth KJ (1995) Posture, comfort, and monitor placement Ergonomics in Design, pp 7-9

Bashiri M, Moslemi A (2013) Simultaneous robust estimation of multi-response surfaces in the presence of outliers. J Ind Eng Int 9(1):1-12

Bashiri M, Farshbaf-Geranmayeh A, Mogouie H (2013) A neuro-data envelopment analysis approach for optimization of uncorrelated multiple response problems with smaller the better type controllable factors. J Ind Eng Int 9(30):1-10

Chung-Chen T, Hong H (2002) Comparison of the tool life of tungsten carbides coated by multi-layer TiCN and TiAlCN for end mills using the Taguchi method. J Mater Proc Technol 123:1-4

Farsani R, Raissi S, Shokuhfar A, Sedghi A (2007) Optimization of carbon fibers made up of commercial polyacrylonitrile fibers using screening design method. Mater Sci Interdiscip J Phys Chem Technol Mater 25(1), ISSN 0137-1339

Ghasemi FA, Raissi S, Malekzadehfard K (2013) Analytical and mathematical modeling and optimization of fiber metal laminates (FMLs) subjected to low-velocity impact via combined response surface regression and zero-one programming. Latin Am J Solids Struct 10(2):391-408

Galitz WO (1997) The essential guide to user interface design: an introduction to GUI design principles and techniques. Wiley, New York

Grandjean E (1980) Fitting the task to the man. Taylor \& Francis, London
Jaschinski-Krutz W (1991) Eyestrain in VDU users: viewing distance and the resting position of ocular muscles. Hum Factors 33:69-83

Jaschinski-Kruza W (1998) Visual strain during VDU work: the effect of viewing distance and dark focus. Ergonomics 33:1449-1465

Juola JF, Tiritoglu A, Pleunis J (1995) Reading text presented on a small display. Appl Ergon 26:227-229

Knoblauch K, Arditi A, Szlyk J (1991) Effects of choromatic and luminance contrast on reading. J Optical Soc Am 8:428-439

Leavitt SB (1995) Lower your VDT monitor. Workplace Ergonomics, 32-35

Legge GE, Pelli DG, Rubin GS, Schleske MM (1985) Psychophysics of reading-I. Normal vision. Vis Res 25:239-252

Legge GE, Rubin GS, Luebker A (1987) Psychophysics of reading-V. The role of contrast in normal vision. Vis Res 27:1165-1177

Mariajayaprakash A, Senthilvelan T, Vivekananthan K (2013) Optimisation of shock absorber process parameters using failure mode and effect analysis and genetic algorithm. J Ind Eng Int 9(1):1-10

Nian CY, Yang WH, Tarng YS (1999) Optimization of turning operation with multiple performance characteristics. J Mater Proc Technol 95:90-96

Ojanpaa H, Nasanen R (2003) Effects of luminance and color contrast on the search of information on display devices. Displays $24: 167-178$

Phadke MS (1989) Quality engineering using robust design. Prentice Hall International Inc

Ross PJ (1996) Taguchi techniques for quality engineering. McGrawHill International Editions, Singapore

Roy RK (2001) Design of experiments using the Taguchi approach: 16 steps to product and process improvement. John Wiley \& Sons, Inc., New York

Sanders MS, McCormick EJ (1993) Human factors in engineering and design. McGraw-Hill, Singapore

Shieh KK, Chen MT (1997) Effects of screen color combination and visual task characteristics on visual performance and visual fatigue. In: proceeding of the National Science Council, ROC (A) 21 , pp 361-368

Shieh KK (2002) Effects of reflection and polarity on LCD viewing distance. Int J Ind Ergon 25:275-282 
Shiek KK, Lin CC (2000) Effects of screen type, ambient illumination, and color combination on VDT visual performance and subjective performance. Int J Ind Ergon 26:527-536

Shokuhfar A, Khalili SMR, Ashenai Ghasemi F, Malekzadeh K, Raissi S (2008) Analysis and optimization of smart hybrid composite plates subjected to low-velocity impact using the response surface methodology (RSM). Thin-Walled Structures, Oxford, England, Vol. 46, pp 1204-1212

Snyder HL, Decker JJ, Loyd CJC, Dye C (1990) Effect of image polarity on VDT task performance. In: Proceedings of the Human Factors Society 34th Annual Meeting, (Santa Monica, 1990) CA, pp 1447-1451

Szeto GP, Lee R (2002) An ergonomic evaluation comparing desktop, notebook, and subnotebook computers. Arch Phys Med Rehabil $83: 527-532$

Taptagaporn S, Saito S (1990) How display polarity and lighting conditions affect the pupil size of VDT operators. Ergonomics 33:201-208

Turville KL, Psihogios JP, Ulmer TR, Mirka GA (1998) The effects of video display terminal height on operator: a comparison of the $15^{\circ}$ and $40^{\circ}$ recommendations. Appl Ergon 29:239-246
Villanueva MGB, Sotoyama M, Jonai H, Takeuchi Y, Saitu S (1996) Adjustments of posture and viewing parameters of the eye to changes in the screen height of the visual display terminal. Ergonomics 39(7):933-939

Wang AH, Chen CH (2003) Effects of screen type, Chinese typography, text/background color combination, speed, and jump length for VDT leading display on users' reading performance. Int J Ind Ergon 31:249-261

Wang WH, Tarng YS (1998) Design optimization of cutting parameters for turning operations based on the Taguchi method. J Mater Process Technol 84:122-129

Wang AH, Chen CH, Chen MT (2002) Effects of leading display design of dynamic information on users' visual performance and visual fatigue. J Chin Inst Ind Eng 19:69-78

Zhu Z, Wu J (1990) On the line standardization on VDT's proper and optimal contrast range. Ergonomics 33(7):925-935 